Rev. Elev. Méd. vét. Pays trop., 1975, 28 (3) : 297-300

\title{
Enquête épidémiologique sur la maladie des muqueuses : Absence de la maladie à Madagascar
}

\author{
par J. BLANCOU (*), A. PROVOST $(* *)$, H. SERRES (***)
}

\section{RESUME}

Une enquête épidémiologique sur la maladie des muqueuses des bovins, par inoculation de sang suspect ou recherche d'anticorps, confime l'absence de cette maladie à Madagascar.

La maladie des muqueuses est une virose des bovins actuellement largement répandue dans le monde.

"L'annuaire de la Santé Animale " F.A.O. - O.I.E. - W.H.O. reconnaît son existence officielle dans quarante et un pays au moins, de chacun des cinq continents.

L'insularité de Madagascar d'une part, et l'existence d'une entérite épizootique chez les zébus malgaches d'autre part, nous ont incité à effectuer une enquête épidémiologique dans ce pays.

En effet :

- L'Ile de Madagascar est située dans l'Océan Indien, dont trois continents riverains, l'Afrique, l'Asie et l'Australie, sont contaminés par le virus. Or les contacts maritimes ou aériens sont fréquents avec ces trois régions géographiques, et seraient l'occasion facile d'un transfert du contage.

(*) Centre National de Recherches Vétérinaires et Zootechniques, B.P. 862, Tananarive, République Malgache. Adresse actuelle: Laboratoire National de l'Elevage et de Recherches Vétérinaires, B.P. 2057, Dakar-Hann, République du Sénégal.

(**) Laboratoire de Farcha, B.P. 433, N'Djamena, République du Tchad.

$\left({ }^{* * *}\right)$ I.E.M.V.T, 10, rue Pierre Curie, 94700 Maisons-Alfort, France.
- Des importations de bovins ont, du reste, été effectuées à plusieurs reprises d'Europe (taurins), d'Afrique du Sud (Afrikander) ou des Etats-Unis (Brahman) à destination de Madagascar.

- Par ailleurs le rôle vecteur des oiseaux migrateurs, évoqué pour la "maladie nodulaire cutanée " (1), aurait pu également jouer dans le cas de la maladie des muqueuses.

- A plusieurs reprises des cas d'entérite épizootique des bovins adultes ont été rapportés à Madagascar (8), dont l'étiologie exacte n'a pas été encore parfaitement élucidée.

Leurs symptômes diarrhéiques auraient pu être le fait de l'action pathogène entérotrope du virus de la maladie des muqueuses.

Ce sont les conditions et les résultats de cette enquête épidémiologique qui constituent l'objet de la présente note.

\section{MATERIEL ET METHODES}

\section{MATERIEL}

L'enquête a été réalisée en deux temps: recherche directe du virus dans le sang des zébus atteints d'entérite épizootique, puis recherche d'anticorps dans les sérums des zébus originaires des différentes régions de l'Ile. 


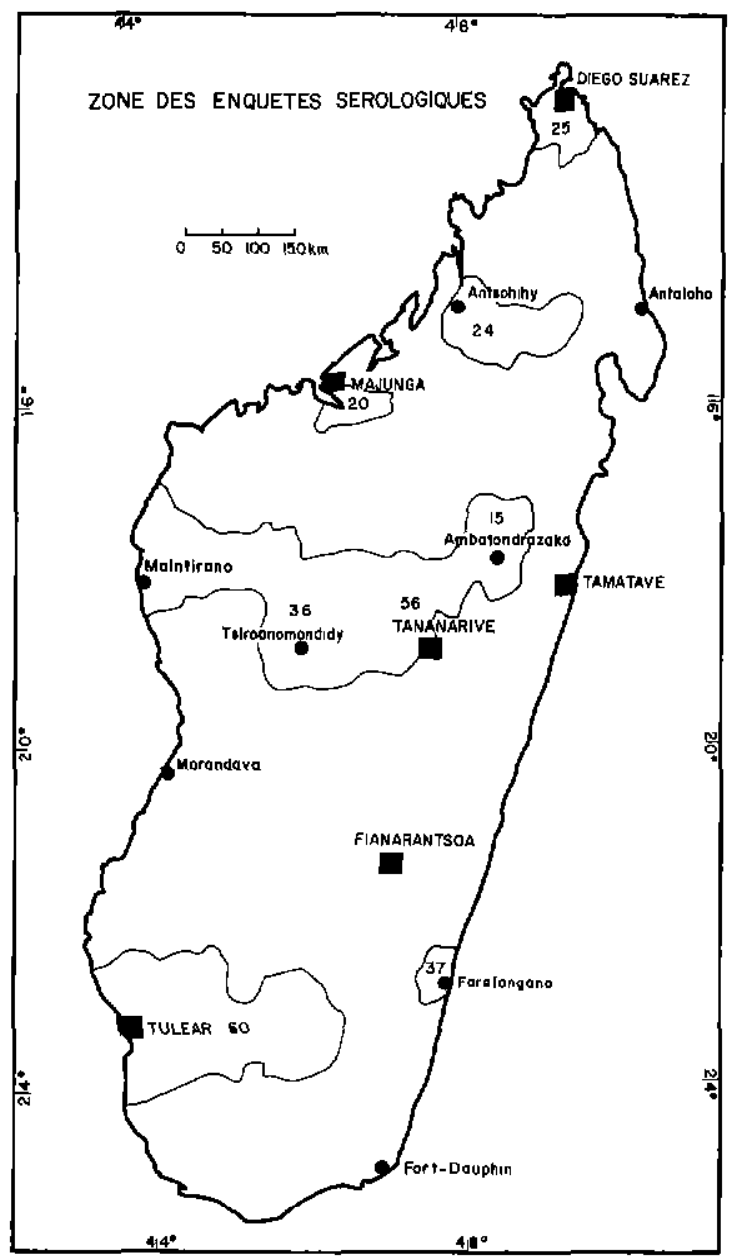

Les prélèvements étaient donc de deux sortes:

\section{Sang hépariné}

$10 \mathrm{ml}$ de sang de zébu atteint d'entérite épizootique sont recueillis stérilement sur $100 \mathrm{uni}$ tés d'héparine, et conservés sous glace jusqu'à l'inoculation à un animal réceptif.

\section{Sérum}

Les sérums sont recueillis par ponction veineuse, en flacons stériles, puis décantés, ou centrifugés si nécessaire. Ils sont ensuite lyophilisés sous le volume de $3 \mathrm{ml}$, pour expédition de Tananarive à Farcha.

Le prélèvement se fait soit lors du sacrifice de l'animal à l'abattoir ( 1 animal sur 3 ), soit lors des vaccinations annuelles contre les charbons (1 animal sur 10).

\section{METHODES}

\section{Recherche directe du virus}

Le sang recueilli sur les malades a été inoculé à des zébus de 9 à 12 mois, 5 heures au plus après son prélèvement. Ces zébus provenaient de stations de recherches où aucun syndrome d'entérite épizootique n'a jamais été signalé.

\section{Recherche d'anticorps}

La recherche des anticorps contre la maladie des muqueuses a été réalisée par la technique de séro-neutralisation précédemment décrite (6), en utilisant du sérum pur ainsi que le recommande SMITH et collab. (9) pour les enquêtes sérologiques. Un échantillon du stock de virus cytopathogène $\mathrm{MD} / \mathrm{Ml}$ (*) est dilué en tampon phosphate à $\mathrm{pH}: 7,2$ (contenant par $\mathrm{ml}: 100 \mathrm{U}$ de Pénicilline, 100 microgrammes de Streptomycine, 25 microgrammes de Néomycine, 50 microgrammes de Kanamycine et 2,5 microgrammes de Fungizone) pour avoir $200 \mathrm{DCP}_{50} / \mathrm{ml}$. On mélange $1 \mathrm{mI}$ des sérums à examiner avec $1 \mathrm{ml}$ du virus; on laisse incuber 1 heure à $37^{\circ} \mathrm{C}$, puis on absorbe le mélange sur des tubes des cultures cellulaires préalablement rincés 3 fois au Hanks. Après une heure d'absorption, on remet en culture dans le milieu de Eagle à 10 p. 100 de sérum de cheval, et on place les tubes sur le tambour d'un rouleur. La lecture se fait le $4^{\mathrm{e}}$ ou $5^{\mathrm{e}}$ jour.

\section{RESULTATS}

\section{Recherche directe du virus}

Cette recherche a été faite au cours d'une série de graves épizooties d'entérite bovine survenues en 1971 dans les régions d'Anjiro (7).

\section{- Foyer d'Anjiro}

25 malades, 6 prélèvements de sang, inoculés sans résultats.

\section{- Foyer d'Ambatondrazaka}

10 malades, 4 prélèvements de sang, inoculés sans résultats.

(*) Souche originaire du Bundesforschungsanstalt für Viruskrankheiten der Tiere, Tübingen, Allemagne fédérale, qui donne en 48 à 72 heures des lésions cytopathiques très nettes. 


\section{- Foyer de Tananarive}

12 malades, 8 prélèvements de sang, inoculés sans résultats. Donc les 18 prélèvements de sangs suspects, inoculés à 18 zébus réceptifs, n'ont provoqué chez eux aucun trouble pouvant évoquer le syndrome "Maladie des muqueuses », ni aucun symptôme d'entérite.

\section{Recherche d'anticorps}

Une enquête sérologique a été effectuée en 1970,1971 et 1972 dans les principales régions d'élevage de Madagascar. La carte annexe indique, par zone, le nombre des sérums prélevés.

Les 273 sérums recueillis ont été utilisés dans des épreuves de séro-neutralisation au Laboratoire de Farcha: aucun de ces sérums ne contenait d'anticorps contre la maladie des muqueuses.

\section{DISCUSSION - CONCLUSION}

Les résultats des deux recherches précédentes nous ont confirmé dans la conviction déjà exposée (8) que la maladie des muqueuses n'avait pas encore fait son apparition à Madagascar.

Cette conviction est fondée sur un certain nombre de faits :

\section{Recherche du virus de la maladie des muqueuses}

Cette recherche a été motivée par les signes de diarrhée observés au cours des cas d’entérite épizootique, diarrhée qui fait également partie du tableau clinique de la maladie des muqueuses.

Mais il est à noter qu'aucun des autres symptômes observés dans la forme typique de cette virose n'a été observé dans les cas d'entérite du zébu malgache : en particulier aucun signe de conjonctivite, de laryngite ni de gingivite.

De même, aucune lésion des muqueuses de la bouche et de la langue, ni de la surface cutanée : seule l'inflammation de la caillette et de l'intestin pouvait évoquer, dans les cas d'entérite malgaches, le tableau nécropsique de la maladie des muqueuses. Du reste, si l'étiologie de l'entérite épizootique du zébu malgache n'est pas parfaitement élucidée, du moins le rôle prépondérant d'Escherichia coli y a-t-il été nettement démontré.
Enfin, aucun rapport, verbal ou écrit, du Service ou du Laboratoire de l'Elevage de Madagascar, n'a jamais fait mention d'un syndrome rappelant celui de la maladie des muqueuses. Si un seul de ces rapports avait fait mention d'une maladie bovine associant ptyalisme, larmoiement, entérite, et lésions cutanées, il eut aussitôt justifié une mission spéciale, tant est grande la hantise d'une apparition de peste bovine ou de fièvre aphteuse dans l'Ile.

\section{Recherche des anticorps}

Pour des raisons pratiques, notre enquête n'a pu porter sur un nombre plus important de sérums que les 273 étudiés.

Néanmoins il a été démontré que, dans les pays d'élevage extensif où sévit la maladie des muqueuses, la proportion de sérums présentant des anticorps dans la population bovine est très élevée: 65 à 90 p. 100 aux U.S.A. ou 75 à 80 p. 100 au Tchad (6), par exemple. Statistiquement donc, si la maladie existait à Madagascar, le tri de 273 sérums sans anticorps n'aurait pu être le fait du hasard.

Par ailleurs, la notion de variantes antigéniques du virus a été introduite par GUNERI (5) et confirmée depuis lors par AYNAUD (3), CILLI (2), FERNELIUS (4). L'un de nous a d'ailleurs pu montrer que si la neutralisation croisée des souches d'Afrique Centrale existait avec les souches mondiales de références, des variations antigéniques pouvaient être isolées en Afrique. Or il se trouve que parmi les souches de référence, la souche MD-Ml qui a été utilisée pour les séro-neutralisations est celle qui couvre le plus grand spectre antigénique (5). Si l'on fait l'hypothèse que des souches malgaches à antigénicité se marquant plus ou moins des souches de référence puissent exister, on doit admettre qu'il n'y a que peu de chances qu'elles n'aient pas laissé une trace sérologique que la souche MD-Ml utilisée n'ait pas révélée.

Tous ces faits, s'ils ne peuvent démontrer ре́remptoirement l'inexistence à la maladie des muqueuses à Madagascar, la rendent infiniment peu probable.

Cette constatation vient encore renforcer notre opinion sur la protection toujours très efficace que confère à Madagascar son insularité, et sur l'intransigeance dont doivent continuer de faire preuve les Services Vétérinaires Malgaches pour conserver le bénéfice de cet avantage à leur élevage national. 


\section{SUMMARY}

Epizootiologic survey on mucosal diseases : absence of the disease in Madagascar

An epizootiologic survey on mucosal disease, after inoculation of suspect blood or search for antibodies, confirms the absence of the disease in Madagascar.

\section{RESUMEN}

Encuesta epidemiologica sobre la enfermedad de las mucosas : ausencia de dicha enfermedad en Madagascar

Una encuesta epidemiologica sobre la enfermedad de las mucosas, mediante jnoculación de sangre sospechosa o busqueda de anticuerpos, confirma su ausencia en Madagascar.

\section{BIBLIOGRAPHE}

1. BUCK (G.), QUESNEL (J. J.), SERRES (H.). Une maladie nouvellement identifiée à Madagascar, la Lumpy skin disease. Rev. Elev. Méd. vét. Pays trop., 1956, 9 (3): 229-235.

2. CILLI (V.) et CASTRUCCI (G.). Aspetti virologici e immunologici della malattia delle mucose del bovino. Boll. Ist. Sieroter. Milanese, 1970, 49: 341-371.

3. CORTHIER (G.) et AYNAUD (J. M.), Maladie des muqueuses: mise en évidence de variations antigéniques entre diverses souches. Ann. Rech. vét, 1973, 4 (1) : 79-86.

4. FERNELIUS (A. L.), LAMBERT (G.) et BOOTH (G. D.). Bovine viral diarrhea virus-host cell interactions: serotypes and their relationship to biotypes by cross neutralization. Am. J. vet. Res., 1971, 32: 229-236.

5. GUNERI (S.). Vergleichende serologische Untersunchungen über Bezichungen zwischen verschie- denen Mucosal Disease Virusstämmen. Thèse vétérinaire, Munich, 1968.

6. PROVOST (A.), BOGEL (K.), BORREDON (C.), MAURICE (Y.). La maladie des muqueuses en Afrique Centrale. Observations cliniques et épizootiologiques. Rev. Elev. Méd. vét. Pays trop., 1967, 20 (1) : 27-49.

7. Rapports annuels du Laboratoire de l'Elevage de Tananarive. Rapports annuels du Service de l'Elevage de Madagascar. Archives Service de l'Elevage de Madagascar et de l'I.E.M.V.T.

8. SERRES (H.), BLANCOU (J.). Entérite épizootique des bovins à Madagascar. Rev. Elev. Méd. vét. Pays trop., 1972, 25 (3) : 357-366.

9. SMITH (R.E.), CLARK (G.W.), REYNOLDS (I. M.), DAMON (R.A.). Serologic survey for infectious bovine Rhinotracheitis and bovine viral diarrhea antibodies. J. Am. vet. med. Ass., 1964, 145 : $40-42$. 